\title{
Involvement of glutathione peroxidases in the occurrence and development of breast cancers
}

Man-Li Zhang ${ }^{1+}$, Hua-Tao Wu ${ }^{2+}$, Wen-Jia Chen ${ }^{1,3}$, Ya Xu1, Qian-Qian Ye ${ }^{1,3}$, Jia-Xin Shen ${ }^{4}$ and Jing Liu ${ }^{1,3^{*}}$ (D)

\begin{abstract}
Glutathione peroxidases (GPxs) belong to a family of enzymes that is important in organisms; these enzymes promote hydrogen peroxide metabolism and protect cell membrane structure and function from oxidative damage. Based on the establishment and development of the theory of the pathological roles of free radicals, the role of GPXs has gradually attracted researchers' attention, and the involvement of GPxs in the occurrence and development of malignant tumors has been shown. On the other hand, the incidence of breast cancer in increasing, and breast cancer has become the leading cause of cancer-related death in females worldwide; breast cancer is thought to be related to the increased production of reactive oxygen species, indicating the involvement of GPxs in these processes. Therefore, this article focused on the molecular mechanism and function of GPxs in the occurrence and development of breast cancer to understand their role in breast cancer and to provide a new theoretical basis for the treatment of breast cancer.
\end{abstract}

Keywords: Glutathione peroxidase, Breast cancer, Reactive oxygen species, Occurrence

\section{Background}

Breast cancer has become the most common cancer and the leading cause of cancer-related deaths in females worldwide, according to a status report on the global cancer burden provided by Globocan 2018 [1]. The current standard treatment for patients with breast cancer includes the combination of surgery, radiation, hormone therapy and chemotherapy drugs, such as anthracyclines, cyclophosphamide, taxanes and platinum compounds [2,3]. As a superficial tumor, the causes of death in patients with breast cancer are reported to be due to cancer metastasis and/or relapse, which are significantly associated with the favorable tumor microenvironment

\footnotetext{
*Correspondence: jliu12@stu.edu.cn

†Man-Li Zhang and Hua-Tao Wu contributed equally to this work

${ }^{1}$ Changjiang Scholar's Laboratory/Guangdong Provincial Key Laboratory for Diagnosis and Treatment of Breast Cancer, Shantou University Medical College, Shantou 515041, China

Full list of author information is available at the end of the article
}

[4]. However, the mechanisms of the occurrence, development, and metastasis of breast cancer are very complicated and overlap, suggesting the necessity of different therapies to treat different subtypes of breast cancer. To achieve the best treatment effect, it is necessary to adopt a customized treatment plan for patients, based on the understanding of the pathogenesis of breast cancer $[5,6]$.

Recent studies have shown that reactive oxygen species (ROS) are involved in the molecular mechanisms of breast cancer occurrence and development [7-9]; ROS can be regulated by glutathione peroxidases (GPxs), which are the key enzymes that maintain ROS homeostasis in vivo through the reduction of ROS [10]. Therefore, based on summaries of the research regarding the relationship between breast cancer and GPxs, this article focused on the molecular mechanism and function of different GPxs and their diverse roles in the occurrence and development of breast cancer, further clarifying the pathogenesis of breast cancer and providing a potential 
direction for further studies on the treatment of breast cancers.

\section{The GPx family and its members}

GPxs are members of a multiple-isozyme family that catalyze the reduction of $\mathrm{H}_{2} \mathrm{O}_{2}$ or organic hydroperoxides to generate water or corresponding alcohols using reduced glutathione (GSH) as an electron donor [11]. Currently, 8 GPxs (GPx1-GPx8) have been identified in mammalian tissues, which exhibit the genetic, structural and dynamic differences and perform common and separate functions [12] (Fig. 1).

Among these GPxs, 5 selenium-dependent GPx isozymes have been identified (Table 1). (1) Classical GPx (GPx1) is reported to be expressed in red blood cells and liver, lung, and kidney tissues and is located in the cytosol, nucleus, and mitochondria. The antioxidant effects of GPx1 are achieved by the direct reduction of hydrogen peroxide and lipid hydroperoxides [13]. (2) Gastrointestinal GPx (GPx2) is only found in the cytosol and nucleus of the gastrointestinal tract. Because of its specific localization, GPx 2 was the first GPx considered to be a barrier to the absorption of hydrogen peroxide [14]. (3) Plasma GPx (GPx3) is present in the mitochondria of several organs, such as the kidney, lung, epididymis, breast, heart, and muscle. As the main antioxidant enzyme in plasma, GPx3 is the only extracellular enzyme in the GPx family that reduces ROS products during normal metabolism or oxidative damage [15]. (4) Phospholipid GPx

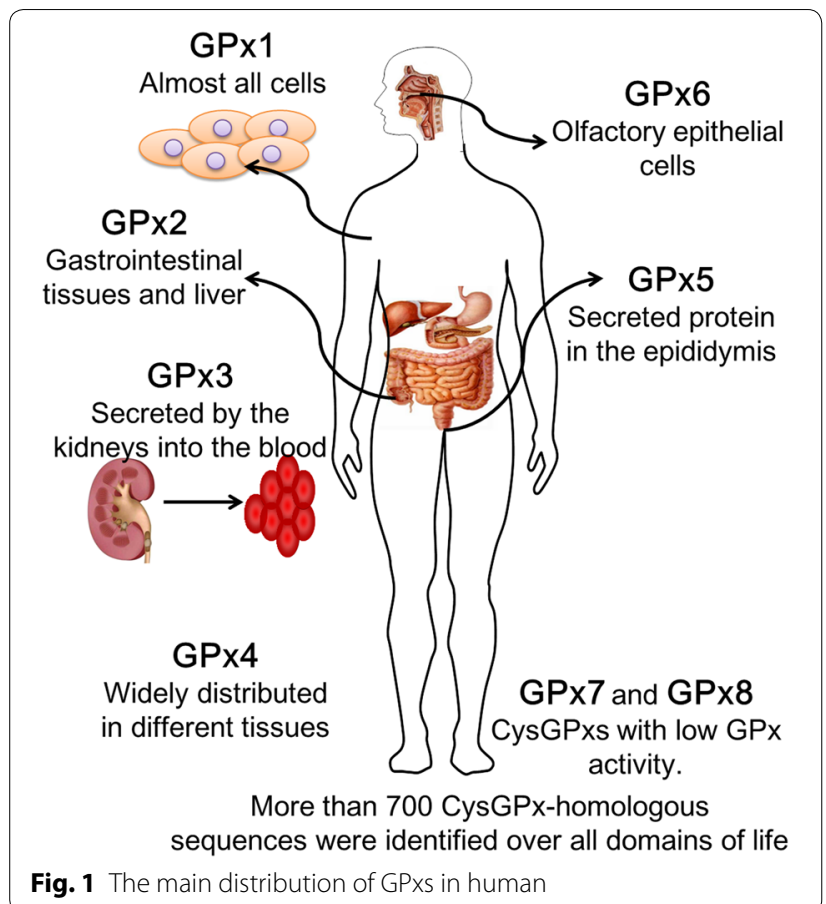

(PHGPx or GPx4) is found in the nucleus, cytosol, and mitochondria of various tissues. As an intracellular selenium protein, GPx4 can directly reduce the production of peroxide phospholipids in the cell membrane [16]. (5) GPx6 is expressed in the olfactory epithelium of humans and pigs [17]. However, GPx6 rarely has been studied, and its function has not been clearly defined.

Among the three non-selenium glutathione peroxidases, GPx 5 is secreted from the epididymis and is thought to protect sperm from peroxide-mediated attacks during maturation. Although the active domain of GPx 5 lacks selenocysteine, it retains antioxidant properties [18]. Another non-selenium glutathione peroxidase, GPx7, which lacks GPx activity, has recently been described as a novel phospholipid hydroperoxide GPx [11, 19-21]; the sequence of GPx7 encodes cysteine in its conserved catalytic motifs [22]. As a non-selenocysteine, GPx8 is a membrane protein that is detected in the endoplasmic reticulum, is present abundantly expressed in the lung, and was identified as a novel member of the GPx family [23].

In general, both the selenium-containing GPxs and non-selenium GPxs are key players in the biological environment and the development of human diseases [17]. The following section will describe the relationships and molecular mechanisms of GPxs in disease development.

\section{ROS are the main molecules involved in the role and mechanism of GPxs in the development of diseases}

ROS, reactive oxygen-containing molecules, are the normal products of aerobic reactions in humans, such as oxidative respiration in mitochondria [24]. ROS are produced by multiple intrinsic mechanisms, and ROS come in a variety of forms, including radical (hydroxyl, superoxide, etc.) or non-radical (hydrogen peroxide, singlet oxygen, etc.) [25]. The intrinsic level of ROS in the intracellular environment plays an important role in the maintenance of cellular homeostasis in vivo; the level of ROS can be dramatically increased by external stimuli or internal stresses and can be toxic to cells [26]. To neutralize ROS, systematic biological detoxification processes are used to maintain their normal level; for example, $N$-acetylcysteine (NAC) in preadipocytes reduces adipogenesis [27]. In organisms, two systems have been developed to neutralize these compounds, including non-enzymatic and enzymatic systems. In addition to superoxide dismutases, catalases, and ascorbate peroxidases, GPxs are important components of the enzymatic systems and are the focus of this article [11] (Table 1). GPxs, which participate in the processes of antioxidant protection and detoxification, are important enzymes that directly regulate ROS levels [28]. The group of GPx enzymes, which 
Table 1 The types of GPxs and their proven substrates

\begin{tabular}{|c|c|c|c|c|c|c|c|}
\hline GPxs & Types & Expressions & Locations & $\begin{array}{l}\text { Oxidizing } \\
\text { substrates }\end{array}$ & $\begin{array}{l}\text { Reducing } \\
\text { substrate }\end{array}$ & $\begin{array}{l}\text { Peroxidatic } \\
\text { residue }\end{array}$ & References \\
\hline GPX1 & Selenium-dependent & $\begin{array}{l}\text { Red cells, liver, lung, } \\
\text { and kidney }\end{array}$ & $\begin{array}{l}\text { Cytosol, nucleus, } \\
\text { and mitochondria }\end{array}$ & $\begin{array}{l}\mathrm{H}_{2} \mathrm{O}_{2} \text {, soluble low } \\
\text { MM hydroper- } \\
\text { oxides }\end{array}$ & GSH & $\mathrm{Sec}$ & {$[17,83]$} \\
\hline GPX2 & Selenium-dependent & $\begin{array}{l}\text { Gastrointestinal } \\
\text { tract }\end{array}$ & Cytosol and nucleus & N.F. & N.F. & $\mathrm{Sec}$ & [118-120] \\
\hline GP×3 & Selenium-dependent & $\begin{array}{l}\text { Kidney, lung, } \\
\text { epididymis, } \\
\text { breast, heart, and } \\
\text { muscle }\end{array}$ & Mitochondria & $\begin{array}{l}\mathrm{H}_{2} \mathrm{O}_{2} \text {, soluble low } \\
\text { MM hydroper- } \\
\text { oxides }\end{array}$ & $\begin{array}{l}\text { GSH, low rate with } \\
\text { thioredoxin and } \\
\text { glutaredoxin }\end{array}$ & $\mathrm{Sec}$ & {$[17,121]$} \\
\hline $\mathrm{GP} \times 4$ & Selenium-dependent & Various tissues & $\begin{array}{l}\text { Nucleus, cytosol, } \\
\text { and mitochondria }\end{array}$ & $\begin{array}{l}\mathrm{H}_{2} \mathrm{O}_{2} \text {, small } \\
\text { hydroperoxides, } \\
\text { hydroperoxides in } \\
\text { complex lipids }\end{array}$ & GSH, Dithiothreitol & $\mathrm{Sec}$ & [122-124] \\
\hline GP×5 & $\begin{array}{l}\text { Non-Selenium- } \\
\text { dependent }\end{array}$ & Epididymis & Extracellular & N.F. & N.F. & Cys & {$[17,125]$} \\
\hline GPx6 & $\begin{array}{l}\text { Selenium-dependent } \\
\text { in human }\end{array}$ & $\begin{array}{l}\text { Olfactory epithe- } \\
\text { lium }\end{array}$ & N.A. & N.F. & N.F. & $\begin{array}{l}\text { Sec (human) } \\
\text { Cys (rats) }\end{array}$ & {$[17,126]$} \\
\hline GPX7 & $\begin{array}{l}\text { Non-Selenium- } \\
\text { dependent }\end{array}$ & Preadipocytes & N.A. & $\mathrm{H}_{2} \mathrm{O}_{2}$ & $\begin{array}{l}\text { GSH, Protein } \\
\text { disulfide isomer- } \\
\text { ase }\end{array}$ & Cys & {$[17,127,128]$} \\
\hline GPx8 & $\begin{array}{l}\text { Non-Selenium- } \\
\text { dependent }\end{array}$ & Lung & $\begin{array}{l}\text { Endoplasmic } \\
\text { reticulum }\end{array}$ & $\mathrm{H}_{2} \mathrm{O}_{2}$ & GSH & Cys & {$[128,129]$} \\
\hline
\end{tabular}

MM molecular mass, N.F. not found, N. A. not available

play an irreplaceable role in the regulation of ROS homeostasis in vivo, has been thought to use GSH as a reducing agent to catalyze the reduction of $\mathrm{H}_{2} \mathrm{O}_{2}$ or organic peroxides to generate water or corresponding alcohols, respectively [17].

It is accepted that an excessive burden of ROS may lead to abnormal cell growth, corresponding changes in intracellular homeostasis and damage to important components of in the cell when the antioxidant defense and/ or DNA repair mechanisms cannot balance the excess oxidants [29]. Oxidative stress, which results from the imbalance between the production and neutralization of ROS, is also reported to be involved in a large number of pathological states, such as Alzheimer's disease [30], Parkinson's disease [31], atherosclerosis [32], heart failure [33], myocardial infarction [34], and hepatic encephalopathy [35]. Importantly, oxidative damage caused by the production of ROS has been linked to the etiology of different types of human cancer $[23,36]$.

In the initial stage of carcinogenesis, ROS play a variety of roles, including mediating the activation of carcinogens, causing DNA damage, and interfering with responses to DNA damage [37-39]. Low levels of ROS can activate host cells in the tumor microenvironment, and promote glucose metabolism in tumors to maintain the high energy consumption of tumors by inducing mitochondrial autophagy, altering key enzymes and genes related glucose metabolism and activating signal pathways; these functions suggest a role of ROS as signaling molecules that favor tumorigenesis. However, a high level of ROS inhibits the occurrence and development of tumors by inducing apoptosis of tumor cells because of their toxic effects [40]. Recently, research on tumor treatment strategies has focused on whether the treatment that opposes or promotes oxidation exert anti-tumor effects. Accumulated evidence suggests that ROS function as second messengers in the determination of cell fate and the modification of various signaling molecules [41]. Therefore, the regulation of ROS homeostasis is crucial for maintaining the health of humans. The exploration and investigation of GPxs, as key enzymes that regulate ROS levels in humans, is of great significance to elucidate the relationship between GPxs and diseases, including tumors, to further understand the pathogenesis of diseases and to prevent ameliorate and even cure these diseases.

The diverse roles of GPxs in different kinds of tumors have been examined but remain controversial. For example, GPx1 has been reported to prevent oxidative DNA mutations, which in turn may prevent the development of tumors [42], and research shows that overexpression of GPx1 can reduce tumor growth, indicating its inhibitory effect in tumorigenesis [43]. However, the expression of GPx1 has been reported to be down-regulated in thyroid cancer [44], colorectal cancer [45, 46], and gastric cancer [47], whereas GPx1 has been demonstrated 
to play an oncogenic role in kidney cancer [48], pancreatic cancer [49], and laryngeal squamous cell carcinoma [50]. The abnormal expression of GPx2 was detected in different tumors, and GPx2 was up-regulated in colorectal cancer [51, 52] and down-regulated in prostate intraepithelial neoplasia [53], suggesting that GPx2 plays complex roles in tumorigenesis [23]. Currently, GPx3 is considered a new tumor-suppressor gene [23], and its hypermethylation, which is associated with the further down-regulation of GPx3, was observed in patients with Barrett's esophagus [54], endometrial adenocarcinoma [55] and prostate cancer [56]. GPx4 is also considered a tumor suppressor because it is down-regulated in tumors $[23,43]$. Current investigations have demonstrated that GPx7 has potential tumor-suppressive effects in gastric and esophageal adenocarcinoma [57-59]. Due to limited research, the roles of GPx5, GPx6, and GPx8 in tumorigenesis are still awaiting clarification.

\section{The role of ROS in the occurrence and development of breast cancer}

The occurrence of breast cancer, the most common malignancy in females worldwide, is generally believed to be significantly associated with the accumulation of genetic damage caused by genetic alterations, which cause uncontrolled cell proliferation and/or abnormal programmed cell death, or apoptosis [60]. Excessive burden of ROS, failure of clearance mechanisms and even lack of antioxidants may lead to the accumulation of ROS and to oxidative stress [40], which are associated with genetic damage and breast cancer onset [61-65]. Sies et al. systematically reviewed the oxidative stress from the perspectives of oxidants and antioxidants, and noted that oxidants with vastly different half-lives may be observed at the site of generation or be transported to distant target sites where they exert oxidant activities in cell metabolism [63]. On the other hand, antioxidants can protect the cells from incident radiation through specialized pigments and control the levels of reactive species which otherwise might cause a cascade of reactions and lead to the generation of pathological oxidants [63].

Considering the molecular mechanism of ROS in the mammary gland, it appears that the oxidative state is involved in the initial occurrence and development of breast cancer through interference with breast cancer stem cells (CSCs) [66]. Malins et al. found that oxidative stress changed the redox potential of the breast, leading to drastic changes in the DNA base lesions, which are conducive to oxidative conditions and breast cancer formation [64]. Interestingly, a positive feedback loop between miR526b/655 and oxidative stress was identified in breast cancer, and the loop promotes tumor growth and metastasis [67]. Rodrgues et al. analyzed the lipid profile and aquaporin expression under conditions of oxidative stress in different types of breast cancer cells and predicted the subsequent metabolic reprogramming of cancer cells and adaption to stress and resistance to therapies [68].

The development of drug resistance is a challenge for the use of adjuvant therapies in breast cancer patients [69], and studies suggest that ROS may play an important role in the production of drug-resistant cells [70]. Zhong et al. demonstrated that oxidative stress and $\mathrm{H}_{2} \mathrm{O}_{2}$ treatment led to a marked increase in senescence-associated $\beta$-galactosidase activity but only to minimal apoptotic cell death in CSCs, suggesting that ROS triggered the induction of senescence and exhibited therapeutic potential in the eradication of drug-resistant CSCs [8]. However, the increase in ROSs induced by drugs seems to play a different role compared to the role of ROS originally generated in malignant tumors. In the treatment of breast cancer, anti-estrogen tamoxifen, the drug most often used for the long-term treatment of early breast cancer, can induce apoptosis in many cells, and this effect may be mediated by ROS generation in the mitochondria of breast cancer cells [71].

\section{The role of GPxs in breast cancer}

As mentioned above, ROS is closely related to the molecular mechanism of breast cancer progression, and ROS can be directly regulated by GPxs, which eliminate organic peroxides at the expense of GSH [10]. The following section will illustrate the relationship between different GPxs and breast cancer and their underlying molecular mechanisms to provide opportunities for further investigation and research and to benefit patients with breast cancer (Table 2).

\section{GPx1}

The GPx1 gene, which encodes the first identified selenoprotein, is located on chromosome 3p21 [72, 73]. Previous research has shown that GPx1 is an effective antioxidant enzyme that cannot be replaced by any other selenoprotein to protect against generalized oxidative stress [74-76]. When cancerous cells are generated, the expression of GPx1 is abnormal, causing intracellular ROS dysfunction [77, 78]. Due to its antioxidant properties, GPx1 is thought to be highly effective in preventing the ROS-mediated initiation of cancer.

In breast cancer, transcription factor AP-2 gamma (TFAP2C) is an important transcription factor that regulates estrogen receptor-alpha (ER $\alpha)$ and c-ErbB2/HER2 (Her2), which are involved in the establishment of the gene expression pattern observed in different clinical phenotypes of breast cancer $[79,80]$. Interestingly, Kulak et al. confirmed that TFAP2C regulated GPx1 expression 
Table 2 The expression, function and potential mechanism of GPxs in breast cancers

\begin{tabular}{|c|c|c|c|}
\hline GPxs & Location & Main findings in breast cancers & References \\
\hline \multirow[t]{7}{*}{ GPX1 } & $3 p 21.31$ & TFAP2C regulates GPx1 promoter through an AP-2 regulatory region & {$[81]$} \\
\hline & & GPx1 polymorphism in modifying stress response & {$[82]$} \\
\hline & & Decreased GPx1 expression & {$[83]$} \\
\hline & & Loss of heterozygosity and allelic differences of GPx1 & {$[88]$} \\
\hline & & Pro198Leu-associated decreased GPX1 activity with high breast cancer risk & {$[89,92]$} \\
\hline & & The Leu198Leu genotype of GPx-1 & {$[91]$} \\
\hline & & Regulate the sensitivity to doxorubicin & {$[93]$} \\
\hline \multirow[t]{3}{*}{ GPX2 } & $14 q 23.3$ & Upregulated in breast cancer cells & {$[19]$} \\
\hline & & Overexpression in rat breast cancer & {$[98]$} \\
\hline & & Highly regulated by retinoic acid & {$[94]$} \\
\hline \multirow[t]{2}{*}{ GPX3 } & $5 q 33.1$ & Downregulated in aggressive phenotype of breast cancer & {$[103]$} \\
\hline & & $\begin{array}{l}\text { An independent predictive marker for local recurrence of early-stage invasive cancer } \\
\text { patients }\end{array}$ & {$[104]$} \\
\hline \multirow[t]{3}{*}{ GPX4 } & $19 p 13.3$ & Downregulated in breast cancer cells & {$[19]$} \\
\hline & & Predict poor prognosis of invasive ductal breast carcinoma & {$[106]$} \\
\hline & & $\begin{array}{l}\text { Impaired GPx4 expression in peripheral blood monocytes as a biomarker for increased } \\
\text { breast cancer risk }\end{array}$ & {$[111]$} \\
\hline GPX5 & $6 p 22.1$ & Downregulated in breast cancer cells & {$[19]$} \\
\hline GP×6 & $6 p 22.1$ & Downregulated in breast cancer cells & [19] \\
\hline GPX7 & $1 \mathrm{p} 32.3$ & Downregulated in breast cancer cells & {$[19]$} \\
\hline GPx8 & $5 q 11.2$ & Not available & \\
\hline
\end{tabular}

by directly binding to the GPx1 promoter, which contains an AP-2 regulatory region, and the methylation of the CPG island in the GPx1 promoter region prevented the binding of TFAP2C by encompassing the AP-2 regulatory region [81]. As expected, compared to those healthy control subjects, the tissues of breast cancer patients exhibit significantly increased lipid peroxidation, which is dependent on functional polymorphism of GPx1 [82]. However, compared to that in non-malignant tissues, the expression level of GPx1 in tumor tissues was significantly decreased by $7.4 \%$ [83].

The controversial expression pattern of GPx1 in breast cancers requires further investigation to determine its molecular functions. Artificial overexpression of GPx1 showed an increased capacity to rescue breast cancer cells from the cell cycle arrest caused by hyperoxic stress, indicating the involvement of both peroxide-derived free radicals and nonperoxide-derived species during the deleterious process [84]. Gouaze et al. found that increased GPx1 levels significantly increased the resistance of breast cancer T47D cells to doxorubicin partially by interfering with the activation of the sphingomyelin-ceramide pathway [85]. Although such research is limited, the overexpression of GPx1 in breast cancer is thought to promote the occurrence and development of breast cancer.
Hence, due to the controversial evidence, exploring the molecular regulation of GPx1 expression and activity is very important for understanding the mechanisms of cancers. Frequent loss of heterozygosity $(\mathrm{LOH})$ on chromosome $3 p$ in lung tumors was associated with low GPx1 enzyme activities, which may affect the prognosis of lung cancer patients [86]. Moscow et al. first reported a polymorphism in GPx1, namely, a substitution at codon 198 of either proline (Pro) or leucine (Leu), Pro198Leu (SNP: 1050450), in lung cancer [87]. In a Macedonian population, the GPx1 Pro198Leu genotype showed an overall protective effect on prostate cancer risk, and erythrocyte GPx1 activities were significantly decreased in prostate cancer patients compared with controls [73]. Similarly, in breast cancer, $\mathrm{LOH}$ at this locus occurred in approximately $36 \%$ of breast cancer tissues, and GPx1 with a leucine-containing allele exhibited lower GPx1 activities in response to stimulation than GPx1 a proline-containing allele [88]. Ravn-Haren et al. showed similar results, namely, that Pro198Leu-associated GPx1 activities were decreased in breast cancer but were associated with increased breast cancer risk among Danish females [89]. In addition to the Leu198Leu genotype in the GPx1 gene, the Ala16Ala genotype in the manganese superoxide dismutase $(\mathrm{MnSOD})$ gene, the most significant enzyme that protects against ROS in the human body [90], was also 
associated with an increased risk of breast cancer [91]. It is suggested that Leu carriers with the Pro198Leu GPx1 allele had a 1.9-fold increased risk of non-ductal breast cancer and a 2.6-fold increased risk of developing grade 3 ductal tumors [92]. These results indicated that the Pro198Leu polymorphism in GPx1 and the associated LOH are factors of significance in breast cancer development.

Regarding treatment strategies, it is suggested that the marked decrease in GPx1 expression may be the major mechanism of tumor sensitization to anthracyclines [93] and that GPx1 can partially inhibit doxorubicin-induced cell death-related signaling in breast cancer by interfering with the activation of the sphingomyelin-ceramide pathway [85]; these findings suggest that tumor regression in response to chemotherapy was correlated with the inhibition of GPx1 activity and confirmed the role of GPx1 in the occurrence and development of breast cancer (Fig. 2).

\section{GPx2}

The selenium-dependent glutathione peroxidase GPx-GI encoded by GPx2 is highly expressed in gastrointestinal epithelial cells and occasionally in breast tissue [94]. In addition to normal tissues, it has been reported that GPx2 is upregulated in a variety of tumor cells $[76,95]$ and is associated with tumor cell proliferation and poor prognosis of patients [96, 97].

In breast cancer, GPx2 is commonly overexpressed in the mammary carcinomas of mouse models of breast cancer induced by carcinogens, which is consistent with its up-regulation in human breast cancer [19]. As expected, the inhibition of GPx2 expression by siRNA led to significant growth inhibition in both rat and human breast cancer cell lines $[19,98]$. Chu et al. confirmed that in MCF-7 cells, which a low aggressive breast cancer cell line, the expression of GPx2 can be substantially up-regulated by retinoic acid [94]. Due to its potential function in the occurrence and development of breast cancer, GPx2 is suggested as a potential target for the prevention and treatment of breast cancer. However, the current research on the relationship between GPx2 and breast cancer is limited and there are still many gaps in the research regarding its regulatory mechanisms.

\section{GPx3}

As mentioned above, elevated levels of ROS play a crucial role in the progression of breast cancer [99]. As the only extracellular enzyme in the GPx family, GPx3 is an essential enzyme that is responsible for removing ROS products during normal metabolism or oxidative damage in healthy tissues [76]. Lee et al. observed a high frequency of promoter hypermethylation and progressive loss of GPx3 expression in Barrett's esophagus and its associated lesions, and these authors also confirmed the known function of GPx3 as a potent antioxidant [54]. In human thyroid cancer, GPx3 is frequently methylated, and the expression of GPx3 is regulated by methylation of the promoter region, and this methylation is related to tumor size and lymph node metastasis through the inhibition

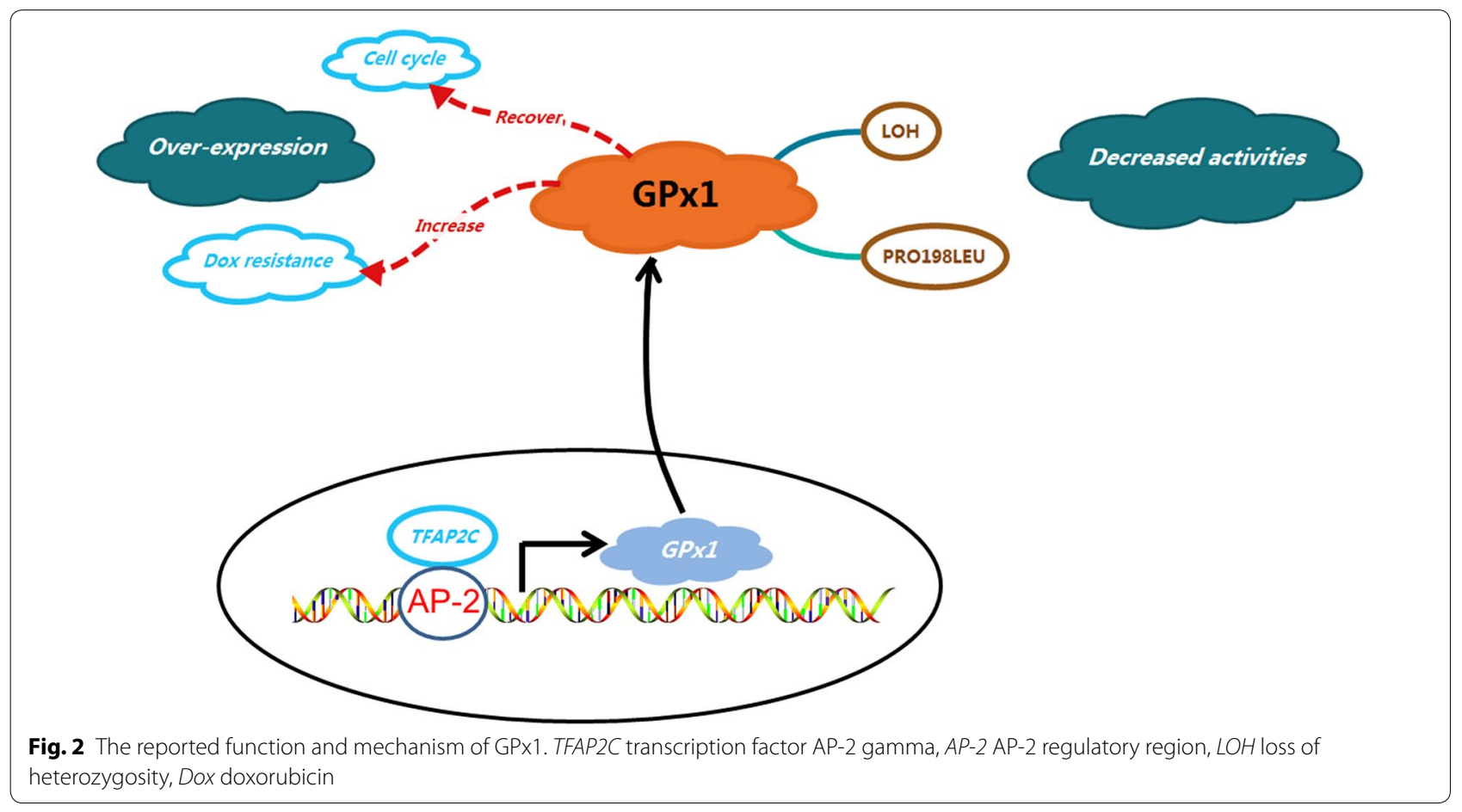


of Wnt/ $\beta$-catenin signaling [100]. The methylation of the GPx3 promoter was also observed in hepatocellular carcinoma (HCC) tissue [101] and gastric carcinoma [102], possibly leading to subsequent carcinogenesis and cancer cell progression. These findings suggest that epigenetic inactivation and regulation of the GPx3 pathway may be critical in the development and progression of different types of cancers.

Consistently, the GPx3 levels were reported to be down-regulated in aggressive inflammatory breast cancer (IBC) carcinoma tissues compared to non-IBC tissues, and this down-regulation was associated with hypermethylation of the GPx3 promoter [103]. In addition, a low level of GPx3 is an independent predictive marker of the local recurrence of early-stage invasive breast cancer in patients undergoing breast-conserving surgery and radiotherapy, regardless of the patient's clinicopathological parameters [104]; this observation suggests that inactivation of the GPx3 gene by hypermethylation of the promoter may contribute to breast cancer progression.

\section{GPx4}

GPx4 was discovered in 1982 by Ursini et al. [105], and GPx4 is the only known enzyme able to reduce lipid peroxides bound to cell membranes [106, 107]. In contrast to other GPxs, GPx4 is the only one that reduces the hydroperoxides of lipoproteins and complex lipids, such as cholesterol, cholesterol esters, and phospholipids [108], to protect mitochondrial ATP generation from oxidative damage [109]. Recently, GPx4 was predicted to be a specific target for new pharmacological therapies aimed at activating or inhibiting cell death in cancer or degenerative diseases [110].

Interestingly, GPx4 expression was down-regulated in breast cancer cells compared with normal breast cells [19]. A recent study showed a strong negative correlation between breast tumor grade progression and GPx4 expression in breast cancer tissues, and its downregulation may be related to the poor prognosis of patients with invasive ductal carcinoma of the breast [106]. In addition, impaired GPx4 expression in peripheral blood monocytes was shown to be a biomarker of increased risk of breast cancer [111]. However, the specific mechanism of GPx4 in the occurrence of breast cancer has not been elucidated and requires further study.

\section{Other GPxs}

As studies of the functions of GPx5, GPx6 and GPx7 in the development of breast cancer are limited, it is difficult to determine their underlying mechanisms. Rusolo et al. systemically examined the expression of GPxs in breast cancer cell lines and found that GPx 5 and GPx7 were down-regulated in the human breast cancer MCF-7 and MDA-MB-231 cell lines and GPx6 was also downregulated in MDA-MB-231cells compared with healthy breast MCF-10A cells [19]. However, relevant research on their roles in breast cancer and the regulatory mechanisms are still lacking and needs to be supplemented. The expression pattern and function of GPx8 in breast cancer have not been reported.

\section{Therapeutic implications}

Based on the role of ROS in breast cancer, several reagents have been reported to be potential therapeutic methods for patients with breast cancer. Methanolic extract of corn silk, which induces apoptosis in breast cancer cells was proposed to be a novel anti-tumor agent that acts by increasing ROS production and decreasing GSH levels in a dose-dependent manner [112]. De et al. reported the therapeutic potential of another natural quinazoline derivative that promoted oxidative stress and increased ROS production [113]. George et al. proposed Rubus bioactive compounds as another reagent to induce apoptotic cell death in human breast cancer cells [114]. In triple-negative breast cancer (TNBC) cells treated with isorhamnetin $(\mathrm{IH})$ and chloroquine $(\mathrm{CQ})$, ROS induced Drp1-dependent mitochondrial fission and apoptosis by mediating the activation and mitochondrial translocation of CaMKII; this study suggested IH as a novel chemotherapeutic agent [115].

As an important group of antioxidative enzymes, the normal levels of GPxs help to control the level of reactive species. The identification of ways to improve the expression of GPxs in malignant tumors, especially in breast cancers, is further research direction. However, to date, the methods used to increase GPx expression are mainly the artificial over-expression of GPxs through transfections or infections. After confirming the clinical significance and potential therapeutic role of GPx3 in tumor recurrence after liver transplantation [116], Qi et al. constructed and verified a delivery system by composed of mesenchymal stem cells derived from human induced pluripotent stem cells (hiPSCMSCs) to increase the expression level of GPx3 in vivo [117]. The engineered hiPSC-MSCs successfully delivered GPx3 to the liver and ameliorated hepatic injury by inhibiting hepatic senescence [117]; this result provides potential therapeutic strategies and prospects for breast cancer treatment. Based on the review of key role of ROS in the occurrence and development of breast cancer, it is inspired that the changed expression level of GPxs may achieve the therapeutic purpose after determining its clinical significance in breast cancer. For example, the inactivation of GPx3 may contribute to the progression of breast cancer [103, 104]. So the delivery of GPx3 to breast tumor tissues 
through hiPSC-MSCs or other methods may promote its expression, and reduce the influence of ROS on the progression of breast cancer accordingly, finally achieve the goal of treating breast cancer. Although there is no corresponding research report at present, this method undoubtedly provides a new idea and strategy for the treatment of breast cancer.

\section{Conclusion}

Breast cancer is a serious threat to the health of women around the world, and the mechanism of its occurrence and treatment is of great significance. The identification of the relationship between GPxs and breast cancer is valuable for the discovery of potential therapeutic targets for breast cancer. A greater understanding of the pathogenesis of breast cancer will increase the chances of identifying a cure. At present, there has been substantial research on the relationship between GPxs and breast cancer, but the research is still very limited. This review provides a systematic and clear summary of the relationship between GPxs and breast cancer to elucidate the role of GPxs in the pathogenesis of breast cancer and to provide a clear direction. There is a large gap waiting to be filled by subsequent researchers to yield better therapeutic targets and methods to cure breast cancer, and the role of GPxs in breast cancer should be studied as an extremely important issue. Additional studies of GPxs in breast cancer may 1 day lead to a cure for this disease that is so devastating to women's lives and health.

\section{Abbreviations \\ CQ: Chloroquine; CSCs: Cancer stem cells; ERa: Estrogen receptor-alpha; GPxs: Glutathione peroxidases; GSH: Glutathione; HCC: Hepatocellular carcinoma; hiPSC-MSCs: Mesenchymal stem cells drived from human induced pluripotent stem cells; IBC: Inflammatory breast cancer; IH: Isorhamnetin; LOH: Loss of heterozygosity; MnSOD: Manganese superoxide dismutase; NAC: N-acetyl- cysteine; PHGPX: Phospholipid GPx; ROS: Reactive oxygen species; TNBC: Triple-negative breast cancer; TFAP2C:Transcription factor AP-2 gamma.}

\section{Acknowledgements}

We are thankful to Prof. Guan-Wu Li for his valuable advice and English editing.

\begin{abstract}
Authors' contributions
$J \mathrm{~L}$ contributed to the conception and design of the study. MZ, HW, and JL organized the database, searched the literature, structured and carefully drafted the manuscript. WC, YX, QY, and JS analyzed and interpreted the data, drafted and revised carefully the manuscript. JL critically revised the original manuscript. All authors contributed to manuscript revision. All authors read and approved the final manscript.
\end{abstract}

\section{Funding}

This work was supported by the National Natural Science Foundation of China (Nos. 81501539), the Natural Science Foundation of Guangdong Province (No. 2016A030312008), the Li Ka Shing Foundation Grant for Joint Research Program between Shantou University and Technion-Israel Institute of Technology (No. 43209501), and "Dengfeng Project" for the construction of high-level hospitals in Guangdong Province-the First Affiliated Hospital of Shantou University Medical College Supporting Funding (No. 202003-10).
Availability of data and materials Not applicable.

Ethics approval and consent to participate

Not applicable.

\section{Consent for publication}

Not applicable.

\section{Competing interests}

The authors declare that they have no competing interests.

\section{Author details}

${ }^{1}$ Changjiang Scholar's Laboratory/Guangdong Provincial Key Laboratory for Diagnosis and Treatment of Breast Cancer, Shantou University Medical College, Shantou 515041, China. ${ }^{2}$ Department of General Surgery, the First Affiliated Hospital of Shantou University Medical College, Shantou 515041, China. ${ }^{3}$ Department of Physiology/Cancer Research Center, Shantou University Medical College, Shantou 515041, China. ${ }^{4}$ Department of Hematology, the First Affiliated Hospital of Shantou University Medical College, Shantou, People's Republic of China.

Received: 17 March 2020 Accepted: 17 June 2020

Published online: 22 June 2020

\section{References}

1. Bray F, Ferlay J, Soerjomataram I, Siegel RL, Torre LA, Jemal A. Global cancer statistics 2018: GLOBOCAN estimates of incidence and mortality worldwide for 36 cancers in 185 countries. CA Cancer J Clin. 2018;68:394-424.

2. Ono M, Ogilvie JM, Wilson JS, Green HJ, Chambers SK, Ownsworth T, Shum DH. A meta-analysis of cognitive impairment and decline associated with adjuvant chemotherapy in women with breast cancer. Front Oncol. 2015;5:59.

3. Liu J, Shen JX, Wen XF, Guo YX, Zhang GJ. Targeting Notch degradation system provides promise for breast cancer therapeutics. Crit Rev Oncol Hematol. 2016;104:21-9.

4. Kiricuta I, Willner J, Kolbl O. The clinical relevance of lymphatic and blood-vessel invasion in breast-cancer patients. Oncol Rep. 1995;2:137-41.

5. Perou CM, Sorlie T, Eisen MB, van de Rijn M, Jeffrey SS, Rees CA, Pollack JR, Ross DT, Johnsen H, Akslen LA, et al. Molecular portraits of human breast tumours. Nature. 2000;406:747-52.

6. Cancer Genome Atlas N. Comprehensive molecular portraits of human breast tumours. Nature. 2012;490:61-70.

7. Ma L, Fu Q, Xu B, Zhou H, Gao J, Shao X, Xiong J, Gu Q, Wen S, Li F, et al. Breast cancer-associated mitochondrial DNA haplogroup promotes neoplastic growth via ROS-mediated AKT activation. Int J Cancer. 2018:142:1786-96.

8. Zhong G, Qin S, Townsend D, Schulte BA, Tew KD, Wang GY. Oxidative stress induces senescence in breast cancer stem cells. Biochem Biophys Res Commun. 2019;514:1204-9.

9. Zhu D, Shen Z, Liu J, Chen J, Liu Y, Hu C, Li Z, Li Y. The ROS-mediated activation of STAT-3/NEGF signaling is involved in the 27-hydroxycholesterol-induced angiogenesis in human breast cancer cells. Toxicol Lett. 2016;264:79-86.

10. Li C, Shi L, Chen D, Ren A, Gao T, Zhao M. Functional analysis of the role of glutathione peroxidase (GPX) in the ROS signaling pathway, hyphal branching and the regulation of ganoderic acid biosynthesis in Ganoderma lucidum. Fungal Genet Biol. 2015;82:168-80.

11. Margis R, Dunand C, Teixeira FK, Margis-Pinheiro M. Glutathione peroxidase family_an evolutionary overview. FEBS J. 2008;275:3959-70.

12. Brown KM, Pickard K, Nicol F, Beckett GJ, Duthie GG, Arthur JR. Effects of organic and inorganic selenium supplementation on selenoenzyme activity in blood lymphocytes, granulocytes, platelets and erythrocytes. Clin Sci. 2000;98:593-9.

13. Rotruck JT, Pope AL, Ganther HE, Swanson AB, Hafeman DG, Hoekstra WG. Selenium: biochemical role as a component of glutathione peroxidase. Science. 1973;179:588-90. 
14. Florian S, Krehl S, Loewinger M, Kipp A, Banning A, Esworthy S, Chu FF, Brigelius-Flohe R. Loss of GPX2 increases apoptosis, mitosis, and GPX1 expression in the intestine of mice. Free Radic Biol Med. 2010;49:1694-702.

15. Baez-Duarte BG, Mendoza-Carrera F, Garcia-Zapien A, Flores-Martinez SE, Sanchez-Corona J, Zamora-Ginez I, Torres-Rasgado E, Leon-Chavez BA, Perez-Fuentes R, Multidisciplinary Research Group on Diabetes of the Instituto Mexicano del Seguro S. Glutathione peroxidase 3 serum levels and GPX3 gene polymorphisms in subjects with metabolic syndrome. Arch Med Res. 2014;45:375-82.

16. Imai H, Hakkaku N, Iwamoto R, Suzuki J, Suzuki T, Tajima Y, Konishi K, Minami S, Ichinose S, Ishizaka K, et al. Depletion of selenoprotein GPx4 in spermatocytes causes male infertility in mice. J Biol Chem. 2009;284:32522-32.

17. Brigelius-Flohe R, Maiorino M. Glutathione peroxidases. Biochim Biophys Acta. 1830;2013:3289-303.

18. Aitken RJ. Gpx5 protects the family jewels. J Clin Invest. 2009;119:1849-51.

19. Rusolo F, Capone F, Pasquale R, Angiolillo A, Colonna G, Castello G, Costantini M, Costantini S. Comparison of the seleno-transcriptome expression between human non-cancerous mammary epithelial cells and two human breast cancer cell lines. Oncol Lett. 2017;13:2411-7.

20. Herbette S, Roeckel-Drevet P, Drevet JR. Seleno-independent glutathione peroxidases. More than simple antioxidant scavengers. FEBS J. 2007;274:2163-80.

21. Thisse C, Degrave A, Kryukov GV, Gladyshev VN, Obrecht-Pflumio S, Krol A, Thisse B, Lescure A. Spatial and temporal expression patterns of selenoprotein genes during embryogenesis in zebrafish. Gene Expr Patterns. 2003;3:525-32.

22. Chen YI, Wei PC, Hsu JL, Su FY, Lee WH. NPGPx (GPx7): a novel oxidative stress sensor/transmitter with multiple roles in redox homeostasis. Am J Transl Res. 2016;8:1626-40.

23. Jiao $Y$, Wang $Y$, Guo $S$, Wang G. Glutathione peroxidases as oncotargets. Oncotarget. 2017;8:80093-102.

24. Fink RC, Scandalios JG. Molecular evolution and structure-function relationships of the superoxide dismutase gene families in angiosperms and their relationship to other eukaryotic and prokaryotic superoxide dismutases. Arch Biochem Biophys. 2002;399:19-36.

25. Phull AR, Nasir B, Haq IU, Kim SJ. Oxidative stress, consequences and ROS mediated cellular signaling in rheumatoid arthritis. Chem Biol Interact. 2018;281:121-36.

26. D'Autreaux B, Toledano MB. ROS as signalling molecules: mechanisms that generate specificity in ROS homeostasis. Nat Rev Mol Cell Biol. 2007:8:813-24.

27. Chang YC, Yu YH, Shew JY, Lee WJ, Hwang JJ, Chen YH, Chen YR, Wei PC, Chuang LM, Lee WH. Deficiency of NPGPX, an oxidative stress sensor, leads to obesity in mice and human. EMBO Mol Med. 2013;5:1165-79.

28. Muthukumar K, Rajakumar S, Sarkar MN, Nachiappan V. Glutathione peroxidase3 of Saccharomyces cerevisiae protects phospholipids during cadmium-induced oxidative stress. Antonie Van Leeuwenhoek. 2011;99:761-71.

29. Kruk J, Aboul-Enein HY. Reactive oxygen and nitrogen species in carcinogenesis: implications of oxidative stress on the progression and development of several cancer types. Mini Rev Med Chem. 2017:17:904-19.

30. Ahmad W, ljaz B, Shabbiri K, Ahmed F, Rehman S. Oxidative toxicity in diabetes and Alzheimer's disease: mechanisms behind ROS/RNS generation. J Biomed Sci. 2017;24:76.

31. Umeno A, Biju V, Yoshida Y. In vivo ROS production and use of oxidative stress-derived biomarkers to detect the onset of diseases such as Alzheimer's disease, Parkinson's disease, and diabetes. Free Radic Res. 2017;51:413-27.

32. Yeh CC, Wu JY, Lee GL, Wen HT, Lin P, Kuo CC. Vanadium derivative exposure promotes functional alterations of VSMCs and consequent atherosclerosis via ROS/p38/NF-kappaB-mediated IL-6 production. Int J Mol Sci. 2019;20:6115.

33. Ayoub KF, Pothineni NVK, Rutland J, Ding Z, Mehta JL. Immunity, inflammation, and oxidative stress in heart failure: emerging molecular targets. Cardiovasc Drugs Ther. 2017;31:593-608.

34. Rezvan A. Telomeres, oxidative stress, and myocardial infarction. Eur Heart J. 2017;38:3105-7.
35. Montes-Cortes DH, Novelo-Del Valle JL, Olivares-Corichi IM, Rosas-Barrientos JV, Jara LJ, Cruz-Dominguez MP. Impact of intestinal mannitol on hyperammonemia, oxidative stress and severity of hepatic encephalopathy in the ED. Am J Emerg Med. 2018;36:1570-6.

36. Janicka A, Szymanska-Pasternak J, Bober J. Polymorphisms in the oxidative stress-related genes and cancer risk. Ann Acad Med Stetin. 2013:59:18-28.

37. Pelicano H, Carney D, Huang P. ROS stress in cancer cells and therapeutic implications. Drug Resist Update. 2004;7:97-110.

38. Schumacker PT. Reactive oxygen species in cancer cells: live by the sword, die by the sword. Cancer Cell. 2006;10:175-6.

39. Waris $G$, Ahsan $H$. Reactive oxygen species: role in the development of cancer and various chronic conditions. J Carcinog. 2006;5:14.

40. de Sa Junior PL, Camara DAD, Porcacchia AS, Fonseca PMM, Jorge SD, Araldi RP, Ferreira AK. The roles of ROS in cancer heterogeneity and therapy. Oxid Med Cell Longev. 2017;2017:2467940.

41. Phull AR, Majid M, Haq IU, Khan MR, Kim SJ. In vitro and in vivo evaluation of anti-arthritic, antioxidant efficacy of fucoidan from Undaria pinnatifida (Harvey) Suringar. Int J Biol Macromol. 2017;97:468-80.

42. Baliga MS, Wang H, Zhuo P, Schwartz JL, Diamond AM. Selenium and GPX-1 overexpression protect mammalian cells against UV-induced DNA damage. Biol Trace Elem Res. 2007;115:227-42.

43. Liu J, Du J, Zhang Y, Sun W, Smith BJ, Oberley LW, Cullen JJ. Suppression of the malignant phenotype in pancreatic cancer by overexpression of phospholipid hydroperoxide glutathione peroxidase. Hum Gene Ther. 2006;17:105-16.

44. Metere A, Frezzotti F, Graves CE, Vergine M, De Luca A, Pietraforte D, Giacomelli L. A possible role for selenoprotein glutathione peroxidase (GPX1) and thioredoxin reductases (TrXR1) in thyroid cancer: our experience in thyroid surgery. Cancer Cell Int. 2018;18:7.

45. Hu Y, Benya RV, Carroll RE, Diamond AM. Allelic loss of the gene for the GPX1 selenium-containing protein is a common event in cancer. J Nutr. 2005;135:3021S-4S.

46. Nalkiran I, Turan S, Arikan S, Kahraman OT, Acar L, Yaylim I, Ergen A. Determination of gene expression and serum levels of MnSOD and GPX1 in colorectal cancer. Anticancer Res. 2015;35:255-9.

47. Min SY, Kim HS, Jung EJ, Jung EJ, Jee CD, Kim WH. Prognostic significance of glutathione peroxidase 1 (GPX1) down-regulation and correlation with aberrant promoter methylation in human gastric cancer. Anticancer Res. 2012;32:3169-75.

48. Cheng Y, XU T, Li S, Ruan H. GPX1, a biomarker for the diagnosis and prognosis of kidney cancer, promotes the progression of kidney cancer. Aging. 2019;11:12165-76.

49. Meng Q, Xu J, Liang C, Liu J, Hua J, Zhang Y, Ni Q, Shi S, Yu X. GPx1 is involved in the induction of protective autophagy in pancreatic cancer cells in response to glucose deprivation. Cell Death Dis. 2018;9:1187.

50. Zhang Q, Xu H, You Y, Zhang J, Chen R. High Gpx1 expression predicts poor survival in laryngeal squamous cell carcinoma. Auris Nasus Larynx. 2018;45:13-9.

51. Al-Taie OH, Uceyler N, Eubner U, Jakob F, Mork H, Scheurlen M, BrigeliusFlohe R, Schottker K, Abel J, Thalheimer A, et al. Expression profiling and genetic alterations of the selenoproteins GI-GPx and SePP in colorectal carcinogenesis. Nutr Cancer. 2004:48:6-14.

52. Chiu ST, Hsieh FJ, Chen SW, Chen CL, Shu HF, Li H. Clinicopathologic correlation of up-regulated genes identified using CDNA microarray and real-time reverse transcription-PCR in human colorectal cancer. Cancer Epidemiol Biomark Prev. 2005;14:437-43.

53. Woenckhaus M, Klein-Hitpass L, Grepmeier U, Merk J, Pfeifer M, Wild P, Bettstetter M, Wuensch P, Blaszyk H, Hartmann A, et al. Smoking and cancer-related gene expression in bronchial epithelium and non-smallcell lung cancers. J Pathol. 2006;210:192-204.

54. Lee OJ, Schneider-Stock R, McChesney PA, Kuester D, Roessner A, Vieth M, Moskaluk CA, El-Rifai W. Hypermethylation and loss of expression of glutathione peroxidase-3 in Barrett's tumorigenesis. Neoplasia. 2005; 7:854-61.

55. Falck E, Karlsson S, Carlsson J, Helenius G, Karlsson M, Klinga-Levan K. Loss of glutathione peroxidase 3 expression is correlated with epigenetic mechanisms in endometrial adenocarcinoma. Cancer Cell Int. 2010;10:46.

56. Yu YP, Yu G, Tseng G, Cieply K, Nelson J, Defrances M, Zarnegar R, Michalopoulos G, Luo JH. Glutathione peroxidase 3, deleted or methylated 
in prostate cancer, suppresses prostate cancer growth and metastasis. Cancer Res. 2007;67:8043-50.

57. Peppelenbosch MP, Spaander MC, Bruno MJ. Glutathione peroxidase 7 prevents cancer in the oesophagus. Gut. 2014;63:537-8.

58. Peng D, Hu T, Soutto M, Belkhiri A, Zaika A, El-Rifai W. Glutathione peroxidase 7 has potential tumour suppressor functions that are silenced by location-specific methylation in oesophageal adenocarcinoma. Gut. 2014;63:540-51.

59. Chen Z, Hu T, Zhu S, Mukaisho K, El-Rifai W, Peng DF. Glutathione peroxidase 7 suppresses cancer cell growth and is hypermethylated in gastric cancer. Oncotarget. 2017:8:54345-56.

60. Cebrian A, Pharoah PD, Ahmed S, Smith PL, Luccarini C, Luben R, Redman K, Munday H, Easton DF, Dunning AM, Ponder BA. Tagging single-nucleotide polymorphisms in antioxidant defense enzymes and susceptibility to breast cancer. Cancer Res. 2006;66:1225-33.

61. Cavalieri EL, Stack DE, Devanesan PD, Todorovic R, Dwivedy I, Higginbotham S, Johansson SL, Patil KD, Gross ML, Gooden JK, et al. Molecular origin of cancer: catechol estrogen-3,4-quinones as endogenous tumor initiators. Proc Natl Acad Sci USA. 1997;94:10937-42.

62. Highman B, Greenman DL, Norvell MJ, Farmer J, Shellenberger TE. Neoplastic and preneoplastic lesions induced in female $\mathrm{C} 3 \mathrm{H}$ mice by diets containing diethylstilbestrol or 17 beta-estradiol. J Environ Pathol Toxicol. 1980;4:81-95.

63. Sies H. Oxidative stress: oxidants and antioxidants. Exp Physiol. 1997:82:291-5.

64. Malins DC, Holmes EH, Polissar NL, Gunselman SJ. The etiology of breast cancer. Characteristic alteration in hydroxyl radical-induced DNA base lesions during oncogenesis with potential for evaluating incidence risk. Cancer. 1993;71:3036-43.

65. Calaf GM, Urzua U, Termini L, Aguayo F. Oxidative stress in female cancers. Oncotarget. 2018;9:23824-42

66. Baratta M, Miretti S, Macchi E, Accornero P, Martignani E. Mammary stem cells in domestic animals: the role of ROS. Antioxidants. 2018;8:6.

67. Shin B, Feser R, Nault B, Hunter S, Maiti S, Ugwuagbo KC, Majumder M. miR526b and miR655 induce oxidative stress in breast cancer. Int J Mol Sci. 2019;20:4039.

68. Rodrigues C, Milkovic L, Bujak IT, Tomljanovic M, Soveral G, Cipak Gasparovic A. Lipid profile and aquaporin expression under oxidative stress in breast cancer cells of different malignancies. Oxid Med Cell Longev. 2019;2019:2061830

69. Ponzone R, Biglia N, Jacomuzzi ME, Mariani L, Dominguez A, Sismondi P. Antihormones in prevention and treatment of breast cancer. Ann NY Acad Sci. 2006;1089:143-58.

70. Cho SK, Pedram A, Levin ER, Kwon YJ. Acid-degradable core-shell nanoparticles for reversed tamoxifen-resistance in breast cancer by silencing manganese superoxide dismutase (MnSOD). Biomaterials. 2013;34:10228-37.

71. Razandi M, Pedram A, Jordan VC, Fuqua S, Levin ER. Tamoxifen regulates cell fate through mitochondrial estrogen receptor beta in breast cancer. Oncogene. 2013;32:3274-85.

72. Flohe L, Gunzler WA, Schock HH. Glutathione peroxidase: a selenoenzyme. FEBS Lett. 1973;32:132-4.

73. Arsova-Sarafinovska Z, Matevska N, Eken A, Petrovski D, Banev S, Dzikova S, Georgiev V, Sikole A, Erdem O, Sayal A, et al. Glutathione peroxidase 1 (GPX1) genetic polymorphism, erythrocyte GPX activity, and prostate cancer risk. Int Urol Nephrol. 2009;41:63-70.

74. Ho YS, Magnenat JL, Bronson RT, Cao J, Gargano M, Sugawara M, Funk CD. Mice deficient in cellular glutathione peroxidase develop normally and show no increased sensitivity to hyperoxia. J Biol Chem. 1997:272:16644-51.

75. de Haan JB, Bladier C, Griffiths P, Kelner M, O'Shea RD, Cheung NS, Bronson RT, Silvestro MJ, Wild S, Zheng SS, et al. Mice with a homozygous null mutation for the most abundant glutathione peroxidase, Gpx1, show increased susceptibility to the oxidative stress-inducing agents paraquat and hydrogen peroxide. J Biol Chem. 1998;273:22528-36.

76. Brigelius-Flohe R, Kipp A. Glutathione peroxidases in different stages of carcinogenesis. Biochim Biophys Acta. 2009;1790:1555-68.

77. Ko BW, Han J, Heo JY, Jang Y, Kim SJ, Kim J, Lee MJ, Ryu MJ, Song IC, Jo YS, Kweon GR. Metabolic characterization of imatinib-resistant BCRABL T315I chronic myeloid leukemia cells indicates down-regulation of glycolytic pathway and low ROS production. Leuk Lymphoma. 2016;57:2180-8.

78. Hua X, Deng R, Li J, Chi W, Su Z, Lin J, Pflugfelder SC, Li DQ. Protective effects of L-carnitine against oxidative injury by hyperosmolarity in human corneal epithelial cells. Invest Ophthalmol Vis Sci. 2015;56:5503-11.

79. Woodfield GW, Horan AD, Chen Y, Weigel RJ. TFAP2C controls hormone response in breast cancer cells through multiple pathways of estrogen signaling. Cancer Res. 2007;67:8439-43.

80. Powe DG, Akhtar G, Habashy HO, Abdel-Fatah T, Rakha EA, Green AR, Ellis IO. Investigating AP-2 and YY1 protein expression as a cause of high HER2 gene transcription in breast cancers with discordant HER2 gene amplification. Breast Cancer Res. 2009;11:R90.

81. Kulak MV, Cyr AR, Woodfield GW, Bogachek M, Spanheimer PM, Li T, Price DH, Domann FE, Weigel RJ. Transcriptional regulation of the GPX1 gene by TFAP2C and aberrant CpG methylation in human breast cancer. Oncogene. 2013;32:4043-51.

82. Jablonska E, Gromadzinska J, Peplonska B, Fendler W, Reszka E, Krol MB, Wieczorek E, Bukowska A, Gresner P, Galicki M, et al. Lipid peroxidation and glutathione peroxidase activity relationship in breast cancer depends on functional polymorphism of GPX1. BMC Cancer. 2015:15:657.

83. Krol MB, Galicki M, Gresner P, Wieczorek E, Jablonska E, Reszka E, Morawiec Z, Wasowicz W, Gromadzinska J. The ESR1 and GPX1 gene expression level in human malignant and non-malignant breast tissues. Acta Biochim Pol. 2018;65:51-7.

84. Bilodeau JF, Patenaude A, Piedboeuf B, Carrier C, Petrov P, Faure R, Mirault ME. Glutathione peroxidase-1 expression enhances recovery of human breast carcinoma cells from hyperoxic cell cycle arrest. Free Radic Biol Med. 2002;33:1279-89.

85. Gouaze V, Mirault ME, Carpentier S, Salvayre R, Levade T, AndrieuAbadie N. Glutathione peroxidase-1 overexpression prevents ceramide production and partially inhibits apoptosis in doxorubicin-treated human breast carcinoma cells. Mol Pharmacol. 2001;60:488-96.

86. Hardie LJ, Briggs JA, Davidson LA, Allan JM, King RF, Williams GI, Wild CP. The effect of hOGG1 and glutathione peroxidase I genotypes and 3p chromosomal loss on 8-hydroxydeoxyguanosine levels in lung cancer. Carcinogenesis. 2000;21:167-72

87. Moscow JA, Schmidt L, Ingram DT, Gnarra J, Johnson B, Cowan KH. Loss of heterozygosity of the human cytosolic glutathione peroxidase I gene in lung cancer. Carcinogenesis. 1994;15:2769-73.

88. Hu YJ, Diamond AM. Role of glutathione peroxidase 1 in breast cancer: loss of heterozygosity and allelic differences in the response to selenium. Cancer Res. 2003;63:3347-51.

89. Ravn-Haren G, Olsen A, Tjonneland A, Dragsted LO, Nexo BA, Wallin H, Overvad K, Raaschou-Nielsen O, Vogel U. Associations between GPX1 Pro198Leu polymorphism, erythrocyte GPX activity, alcohol consumption and breast cancer risk in a prospective cohort study. Carcinogenesis. 2006:27:820-5.

90. Chang Y, Wei W, Zhang L, Xu HM. Effects and mechanisms of total glucosides of paeony on synoviocytes activities in rat collagen-induced arthritis. J Ethnopharmacol. 2009;121:43-8.

91. Cox DG, Tamimi RM, Hunter DJ. Gene $\times$ Gene interaction between MnSOD and GPX-1 and breast cancer risk: a nested case-control study. BMC Cancer. 2006:6:217.

92. Meplan C, Dragsted LO, Ravn-Haren G, Tjonneland A, Vogel U, Hesketh J. Association between polymorphisms in glutathione peroxidase and selenoprotein P genes, glutathione peroxidase activity, HRT use and breast cancer risk. PLoS ONE. 2013;8:e73316.

93. Vibet S, Goupille C, Bougnoux P, Steghens JP, Gore J, Maheo K. Sensitization by docosahexaenoic acid (DHA) of breast cancer cells to anthracyclines through loss of glutathione peroxidase (GPX1) response. Free Radic Biol Med. 2008;44:1483-91.

94. Chu FF, Esworthy RS, Lee L, Wilczynski S. Retinoic acid induces Gpx2 gene expression in MCF-7 human breast cancer cells. J Nutr. 1999;129:1846-54.

95. Naiki T, Naiki-Ito A, lida K, Etani T, Kato H, Suzuki S, Yamashita Y, Kawai N, Yasui T, Takahashi S. GPX2 promotes development of bladder cancer with squamous cell differentiation through the control of apoptosis. Oncotarget. 2018;9:15847-59. 
96. Liu T, Kan XF, Ma C, Chen LL, Cheng TT, Zou ZW, Li Y, Cao FJ, Zhang WJ, Yao J, Li PD. GPX2 overexpression indicates poor prognosis in patients with hepatocellular carcinoma. Tumour Biol. 2017;39:1010428317700410

97. Naiki T, Naiki-lto A, Asamoto M, Kawai N, Tozawa K, Etani T, Sato S, Suzuki S, Shirai T, Kohri K, Takahashi S. GPX2 overexpression is involved in cell proliferation and prognosis of castration-resistant prostate cancer Carcinogenesis. 2014;35:1962-7.

98. Naiki-Ito A, Asamoto M, Hokaiwado N, Takahashi S, Yamashita H, Tsuda $\mathrm{H}$, Ogawa K, Shirai T. Gpx2 is an overexpressed gene in rat breast cancers induced by three different chemical carcinogens. Cancer Res. 2007;67:11353-8.

99. Brown NS, Bicknell R. Hypoxia and oxidative stress in breast cancer. Oxidative stress: its effects on the growth, metastatic potential and response to therapy of breast cancer. Breast Cancer Res. 2001;3:323-7.

100. Zhao H, Li J, Li X, Han C, Zhang Y, Zheng L, Guo M. Silencing GPX3 expression promotes tumor metastasis in human thyroid cancer. Curr Protein Pept Sci. 2015;16:316-21.

101. Cao S, Yan B, Lu Y, Zhang G, Li J, Zhai W, Guo W, Zhang S. Methylation of promoter and expression silencing of GPX3 gene in hepatocellular carcinoma tissue. Clin Res Hepatol Gastroenterol. 2015;39:198-204.

102. Peng DF, Hu TL, Schneider BG, Chen Z, Xu ZK, El-Rifai W. Silencing of glutathione peroxidase 3 through DNA hypermethylation is associated with lymph node metastasis in gastric carcinomas. PLOS ONE. 2012; 7:e46214.

103. Mohamed MM, Sabet S, Peng DF, Nouh MA, El-Shinawi M, El-Rifai W. Promoter hypermethylation and suppression of glutathione peroxidase 3 are associated with inflammatory breast carcinogenesis. Oxid Med Cell Longev. 2014;2014:787195.

104. Woolston CM, Al-Attar A, Storr SJ, Ellis IO, Morgan DA, Martin SG Redox protein expression predicts radiotherapeutic response in early-stage invasive breast cancer patients. Int J Radiat Oncol Biol Phys. 2011;79:1532-40.

105. Ursini F, Maiorino M, Valente M, Ferri L, Gregolin C. Purification from pig liver of a protein which protects liposomes and biomembranes from peroxidative degradation and exhibits glutathione peroxidase activity on phosphatidylcholine hydroperoxides. Biochim Biophys Acta. 1982;710:197-211.

106. Cejas P, Garcia-Cabezas MA, Casado E, Belda-Iniesta C, De Castro J, Fresno JA, Sereno M, Barriuso J, Espinosa E, Zamora P, et al. Phospholipid hydroperoxide glutathione peroxidase (PHGPX) expression is downregulated in poorly differentiated breast invasive ductal carcinoma. Free Radic Res. 2007;41:681-7.

107. Ursini F, Maiorino M, Brigelius-Flohe R, Aumann KD, Roveri A, Schomburg D, Flohe L. Diversity of glutathione peroxidases. Methods Enzymol. 1995;252:38-53.

108. Brigelius-Flohe R. Tissue-specific functions of individual glutathione peroxidases. Free Radic Biol Med. 1999;27:951-65.

109. Liang H, Van Remmen H, Frohlich V, Lechleiter J, Richardson A, Ran Q. Gpx4 protects mitochondrial ATP generation against oxidative damage. Biochem Biophys Res Commun. 2007;356:893-8.

110. Maiorino M, Conrad M, Ursini F. GPx4, lipid peroxidation, and cell death: discoveries, rediscoveries, and open issues. Antioxid Redox Signal. 2018;29:61-74.

111. Bermano G, Smyth E, Goua M, Heys SD, Wahle KW. Impaired expression of glutathione peroxidase-4 gene in peripheral blood mononuclear cells: a biomarker of increased breast cancer risk. Cancer Biomark. 2010;7:39-46.

112. Al-Oqail MM, Al-Sheddi ES, Farshori NN, Al-Massarani SM, Al-Turki EA, Ahmad J, Al-Khedhairy AA, Siddiqui MA. Corn silk (Zea mays L.) induced apoptosis in human breast cancer (MCF-7) cells via the ROS-mediated mitochondrial pathway. Oxid Med Cell Longev. 2019;2019:9789241.

113. De AK, Muthiyan R, Mondal S, Mahanta N, Bhattacharya D, Ponraj P, Muniswamy K, Kundu A, Kundu MS, Sunder J, et al. A natural quinazoline derivative from marine sponge hyrtios erectus induces apoptosis of breast cancer cells via ROS production and intrinsic or extrinsic apoptosis pathways. Mar Drugs. 2019;17:658.

114. George BP, Abrahamse H. Increased Oxidative Stress Induced by Rubus Bioactive Compounds Induce Apoptotic Cell Death in Human Breast Cancer Cells. Oxid Med Cell Longev. 2019;2019:6797921.

115. Hu J, Zhang Y, Jiang X, Zhang H, Gao Z, Li Y, Fu R, Li L, Li J, Cui H, Gao N. ROS-mediated activation and mitochondrial translocation of CaMKII contributes to Drp1-dependent mitochondrial fission and apoptosis in triple-negative breast cancer cells by isorhamnetin and chloroquine. J Exp Clin Cancer Res. 2019;38:225.

116. Qi X, Ng KT, Shao Y, Li CX, Geng W, Ling CC, Ma YY, Liu XB, Liu H, Liu J, et al. The clinical significance and potential therapeutic role of GPX3 in tumor recurrence after liver transplantation. Theranostics. 2016;6:1934-46.

117. Qi X, Ng KT, Lian Q, Li CX, Geng W, Ling CC, Yeung WH, Ma YY, Liu XB, Liu $\mathrm{H}$, et al. Glutathione peroxidase 3 delivered by hiPSC-MSCs ameliorated hepatic IR injury via inhibition of hepatic senescence. Theranostics. 2018;8:212-22.

118. Wingler K, Bocher M, Flohe L, Kollmus H, Brigelius-Flohe R. mRNA stability and selenocysteine insertion sequence efficiency rank gastrointestinal glutathione peroxidase high in the hierarchy of selenoproteins. Eur J Biochem. 1999;259:149-57.

119. Wingler K, Muller C, Schmehl K, Florian S, Brigelius-Flohe R. Gastrointestinal glutathione peroxidase prevents transport of lipid hydroperoxides in CaCo-2 cells. Gastroenterology. 2000;119:420-30.

120. Brigelius-Flohe R, Kipp AP. Physiological functions of GPx2 and its role in inflammation-triggered carcinogenesis. Ann NY Acad Sci. 2012;1259:19-25.

121. Zhou C, Pan R, Li B, Huang T, Zhao J, Ying J, Duan S. GPX3 hypermethylation in gastric cancer and its prognostic value in patients aged over 60. Future Oncol. 2019;15:1279-89.

122. Takebe G, Yarimizu J, Saito Y, Hayashi T, Nakamura H, Yodoi J, Nagasawa S, Takahashi K. A comparative study on the hydroperoxide and thiol specificity of the glutathione peroxidase family and selenoprotein P. J Biol Chem. 2002;277:41254-8.

123. Thomas JP, Geiger PG, Maiorino M, Ursini F, Girotti AW. Enzymatic reduction of phospholipid and cholesterol hydroperoxides in artificial bilayers and lipoproteins. Biochim Biophys Acta. 1990;1045:252-60.

124. Godeas C, Tramer F, Micali F, Roveri A, Maiorino M, Nisii C, Sandri G, Panfili E. Phospholipid hydroperoxide glutathione peroxidase (PHGPX) in rat testis nuclei is bound to chromatin. Biochem Mol Med. 1996;59:118-24.

125. Vernet P, Rigaudiere N, Ghyselinck N, Dufaure JP, Drevet JR. In vitro expression of a mouse tissue specific glutathione-peroxidase-like protein lacking the selenocysteine can protect stably transfected mammalian cells against oxidative damage. Biochem Cell Biol. 1996;74:125-31.

126. Tanaka C, Coling DE, Manohar S, Chen GD, Hu BH, Salvi R, Henderson D. Expression pattern of oxidative stress and antioxidant defense-related genes in the aging Fischer 344/NHsd rat cochlea. Neurobiol Aging. 1842;2012(33):e1814-41.

127. Utomo A, Jiang X, Furuta S, Yun J, Levin DS, Wang YC, Desai KV, Green JE, Chen PL, Lee WH. Identification of a novel putative non-selenocysteine containing phospholipid hydroperoxide glutathione peroxidase (NPGPx) essential for alleviating oxidative stress generated from polyunsaturated fatty acids in breast cancer cells. J Biol Chem. 2004;279:43522-9.

128. Toppo S, Vanin S, Bosello V, Tosatto SC. Evolutionary and structural insights into the multifaceted glutathione peroxidase (Gpx) superfamily. Antioxid Redox Signal. 2008;10:1501-14.

129. Yamada Y, Limmon GV, Zheng D, Li N, Li L, Yin L, Chow VT, Chen J, Engelward BP. Major shifts in the spatio-temporal distribution of lung antioxidant enzymes during influenza pneumonia. PLoS ONE. 2012;7:e31494.

\section{Publisher's Note}

Springer Nature remains neutral with regard to jurisdictional claims in published maps and institutional affiliations. 